Proceedings

\title{
Green Optimization of Glutaraldehyde Vapor-Based Crosslinking on Poly(Vinyl Alcohol)/Cellulose Acetate Electrospun Mats for Applications as Chronic Wound Dressings ${ }^{\dagger}$
}

\author{
Marta A. Teixeira *, Joana C. Antunes, M. Teresa P. Amorim and Helena P. Felgueiras
}

Citation: Teixeira, M.A.; Antunes, J.C.; Amorim, M.T.P.; Felgueiras, H.P. Green Optimization of Glutaraldehyde Vapor-Based Crosslinking on Poly(Vinyl Alcohol)/Cellulose Acetate Electrospun Mats for Applications as Chronic Wound Dressings. 2021, 69, 30. https://doi.org/10.3390/CGPM 2020-07193

Published: 4 November 2020

Publisher's Note: MDPI stays neutral with regard to jurisdictional claims in published maps and institutional affiliations.

Copyright: $\odot 2020$ by the authors. Licensee MDPI, Basel, Switzerland. This article is an open access article distributed under the terms and conditions of the Creative Commons Attribution (CC BY) license (http://creativecommons.org/licenses/by/4.0/).
Centre for Textile Science and Technology (2C2T), Department of Textile Engineering, University of Minho, Campus of Azurém, 4800-058 Guimarães, Portugal; joana.antunes@2c2t.uminho.pt (J.C.A.); mtamorim@det.uminho.pt (M.T.P.A.); helena.felgueiras@2c2t.uminho.pt (H.P.F.)

* Correspondence: martaalbertinateixeira@gmail.pt

+ Presented at the First International Conference on "Green" Polymer Materials 2020, 5-25 November 2020; Available online: https://cgpm2020.sciforum.net/.

\begin{abstract}
In the last years, chronic wounds have become more prevalent, leading to a huge burden on the healthcare and social systems by requiring specialized protection. Indeed, wound dressings capable of assisting in the healing process are in urgent need. To that effect, nanofibrous dressings with a structure resembling the extracellular matrix have been engineered by electrospinning from combinations of poly(vinyl alcohol) (PVA) and cellulose acetate (CA) and optimized to endure physiological media contact and mechanical stress after crosslinking. Mats were prepared at different PVA/CA ratios, 100/0, 90/10 and 80/20 v/v\%, at $10 w / v \%$ concentration in acetic acid and water in a $75 / 25 v / v \%$ proportion and processed via electrospinning. Processing conditions were optimized to obtain uniform, continuous, bead free mats, with a flexible structure. The instant solubilization of the PVA portion of the mat in aqueous media was surpassed via crosslinking. Even though there are many chemical agents available to accomplish such task, glutaraldehyde (GA) is by far the most common due to its efficiency, ease of access and processing, and low cost. Further, in its vapor form, GA has demonstrated reduced or no cytotoxic effects. The amount of GA, crosslinking time, temperature, and drying procedure were optimized to guarantee mechanically resilient mats by means of the greenest methodology possible. Indeed, it was determined that GA vapor at $25 \%$ in water could be applied for $7 \mathrm{~h}$ at $60^{\circ} \mathrm{C}$, using $6 \mathrm{~mL}$ of solution, in a $130 \times 120 \mathrm{~mm}^{2}$ mat with optimal results. All traces of GA were then eliminated from the mats in a controlled environment (41\% relativehumidity and $19^{\circ} \mathrm{C}$ ). In the end, it was seen that the mechanical resilience and thermal stability of the mats were improved after the application of the modified, green GA-based crosslinking, revealing the engineered methodology potential for applications in biomedical devices.
\end{abstract}

Keywords: bio-based polymers; wound protection; nanofibrous electrospun mats; green crosslinking process; glutaraldehyde vapor; mechanical resilience

\section{Introduction}

Wound healing is a highly coordinate and complex process that comprises rhythmic interactions of various cells and biomolecules [1]. Shortcomings in this process have affected approximately 40 million patients worldwide, reaching epidemic proportions [2]. Diabetes, aging, cardiovascular diseases, malnutrition, and high levels of local bacterial burden are some of the different disorders that can lead to the appearance of this type of wounds [3]. These conditions or factors trigger a persistent inflammatory response, impair angiogenesis, and cause difficult re-epithelialization, since they disrupt the levels of 
cytokines/growth factors and increase the activity of proteases leading to cell disorders, such as phenotypic changes in neutrophils, decreased action of M2 macrophages, and reduced fibroblast proliferative capacity [4,5]. Therefore, to an effective treatment of CW, these phenomena need to be overcome [6]. The oral administration of high doses of drugs is widely accepted to reach such a goal. However, their efficiency is in many instances compromised due to their low tissue penetration effectiveness and the arise of systemic side effects (off-target action).

Dressings have played an important role in CW treatments, as they allow the direct delivery of bioactive compounds to the affected site, protect the wound bed from physical and mechanical stress, and guarantee a moisture environment and a provisional matrix for cell migration, deposition, and neovascularization, while still maintaining the oxygenation of the wound [2,7]. The architecture and the topography of the wound dressing plays a significant role in the skin regeneration and the healing of the wound. The electrospinning technique has attracted great attention by being capable of producing 3D nanofibrous dressings, from synthetic and natural polymers, with superior advantages over conventional dressing formulations, including high oxygen permeability, high surface to volume ratio, tunable pore size, and structural similarity to the extracellular matrix [8-10]. While synthetic polymers exhibit excellent mechanical properties, flexibility, thermal stability, electrospinnability, and an appropriated degradation profile, like poly(vinyl alcohol) (PVA), they lack cell affinity or cell recognition sites [11]. To overcome this limitation, synthetic polymers have been conjugated with natural polymers, which exhibit superior biocompatibility and low immunogenicity, and some even display intrinsic antibacterial properties. Cellulose acetate (CA) has attracted wide interest in the production of nanofibers due to its biodegradability, biocompatibility, chemical persistence, and thermal constancy $[12,13]$. Its low tensile strength can be overcome by blending with PVA. Still, PVAbased electrospun nanofibrous dressings suffer from water instability. Therefore, crosslinking approaches that resort to green methodologies are in high demand. This process not only prevents the instant dissolution of PVA in aqueous environments, but also improves the mechanical properties of the mats [7-14]. Various crosslinking approaches can be used, namely physical methods that resort to heat and radiation, or chemical agents such as glutaraldehyde (GA), glyoxal, and boric acid [15]. Among the various aldehydes, GA has been the most effective crosslinking agent, with its vapor phase methodology showing low or no detectable cytotoxic effects [16,17]. In this study, electrospun nanofibrous matrices were prepared using different polymer ratios of PVA and CA, and their crosslinking process was optimized according to the structures generated. Conditions were defined aiming to achieve the greenest methodology possible with the lowest environment impact on all stages of production.

\section{Experiments}

\subsection{Materials}

PVA (Mw 78,000, 88\% hydrolyzed) was purchased from Polysciences, Europe $\mathrm{GmbH}$, and CA (39.8 wt. \% acetyl content, Mw 30,000) was acquired from Sigma. The acetic acid (glacial) was purchased from Merck, while glutaraldehyde (GA, 25\% aqueous solution) was obtained from Sigma.

\subsection{Methods}

\subsubsection{Fabrication of Nanofibrous Meshes}

Polymeric solutions of PVA/CA were prepared at $10 \%(w / v)$ in acetic acid/distilled water at $75 / 25 \%(v / v)$. Polymer solutions were continuously stirred at $40{ }^{\circ} \mathrm{C}$ for $4 \mathrm{~h}$. PVA and CA were combined at varying ratios: 100/0 (or 100 PVA), 90/10, and 80/20\% (v/v). A fixed voltage of $25 \mathrm{kV}$ was applied to the steel capillary needle with an inner diameter of 18 Gauge $(\mathrm{G})$. The distance between the needle tip and the aluminum collector was estab- 
lished at $18 \mathrm{~cm}$, and the solution feeding rate was set at $0.8 \mathrm{~mL} / \mathrm{h}$. Temperature and relative humidity $(\mathrm{RH})$ were controlled and maintained at $20-22{ }^{\circ} \mathrm{C}$ and $65-70 \%$, respectively. After production, mats were stored in a desiccator with a controlled $\mathrm{RH}$ of $\approx 41 \%$ and at $19^{\circ} \mathrm{C}$.

\subsubsection{Crosslinking Process}

PVA/CA meshes were crosslinked in GA vapor with the purpose of increasing their stability in aqueous media. The first approach followed consisted in drying meshes of 130 $\times 120 \mathrm{~mm}^{2}$ for $72 \mathrm{~h}$ at $40^{\circ} \mathrm{C}$, to eliminate residual water molecules, being then placed in a vacuum-sealed desiccator with $15 \mathrm{~mL}$ of GA solution $(2.65 \mathrm{M})$ and left at room temperature (RT) or heated at $60^{\circ} \mathrm{C}$ during $2,4,6,7$, and $8 \mathrm{~h}$. Residual GA was eliminated via two drying processes, one at $60^{\circ} \mathrm{C}$ for $24 \mathrm{~h}$ and another at $45^{\circ} \mathrm{C}$ for $24 \mathrm{~h}$. Removal of GA was also attempted via sonication at RT and orbital shaking at $37^{\circ} \mathrm{C}(100 \mathrm{rpm})$, both for 15 and $30 \mathrm{~min}$, with water change every $5 \mathrm{~min}$, and using a solution of glycine $(0.26 \mathrm{M})$ at 0.5 and $2 \%(v / v)$ in orbital stirring at $37^{\circ} \mathrm{C}$ for 15 and $30 \mathrm{~min}$. In a second approach, the amount of GA solution $(2.65 \mathrm{M})$ was reduced to $6 \mathrm{~mL}$, and the meshes, prepared in equal conditions to those described in approach one, were vacuum-sealed in a desiccator and heated at $60^{\circ} \mathrm{C}$ and $7 \mathrm{~h}$ (optimal time determined by approach one). Here, residual GA was eliminated over time by storing the meshes in a controllable environment of $41 \% \mathrm{RH}$ and at $19{ }^{\circ} \mathrm{C}$.

\subsubsection{Fiber Diameters}

The average fiber diameter of the uncrosslinked and crosslinked electrospun meshes was determined by measuring 100 fiber sites in six scanning electron microscopy (SEM) micrographs captured at 50,000×, using the ImageJ software. Samples were covered with a thin film $(10 \mathrm{~nm})$ of Au-Pd (80-20 wt. \%) using a 208HR high-resolution sputter coater (Cressington Company, Watford, UK) coupled to an MTM-20 Cressington high-resolution thickness controller, and observed via FEG-SEM (NOVA 200 Nano SEM, FEI Company, Hillsboro, OR, USA) using an electron accelerating voltage of $10 \mathrm{kV}$.

\section{Results and Discussion}

Uniform, bead free nanofibrous mats were successfully produced from PVA/CA solutions with an average fiber diameter of 223,217 , and $194 \mathrm{~nm}$ for polymer ratios of 100/0, 90/10, and 80/20, respectively (example in Figure 1a). However, the obtained electrospun nanofibrous meshes were unstable in water, dissolving instantly [18]. A crosslinking process with GA vapor was thus applied. Optimizations were initiated with the 80/20 PVA/CA ratio, since a smaller number of hydroxyl groups were available to react with the aldehydes from GA and, this way, form acetal bonds [13,15]. In a first approach, the vapor phase crosslinking was accomplished using $15 \mathrm{~mL}$ of GA $(2.56 \mathrm{M})$ and exposing the vacuum-sealed mats to RT or heat at $60^{\circ} \mathrm{C}$ for $2,4,6,7$, and $8 \mathrm{~h}$. Samples processed at RT were unsuccessful. The optimal exposure time at $60^{\circ} \mathrm{C}$ was established at $7 \mathrm{~h}$, since with smaller periods of time, the meshes were not efficiently reticulated, degrading upon contact with water, and after $8 \mathrm{~h}$ of treatment, the mats gained a yellowish coloration. After crosslinking, the average fiber diameter increased considerably from 194 to $343 \mathrm{~nm}$ due to the reaction with GA. This was found as evidence of this compound excess on the fibers (Figure $1 \mathrm{~b}$ ). Evaporation processes were then employed at $60{ }^{\circ} \mathrm{C}$ and $45^{\circ} \mathrm{C}$ for $24 \mathrm{~h}$ to remove the entrapped GA. Fibers became yellowish and rigid using the $60^{\circ} \mathrm{C}$ evaporation process. At $45{ }^{\circ} \mathrm{C}$, the mats retained their original color; however, this was not enough to efficiently eliminate the GA from the nanofibers. Three different washing procedures were thus employed: (1) sonication at RT, (2) orbital shaking (100 rpm) at $37^{\circ} \mathrm{C}$, and washing in a $0.26 \mathrm{M}$ glycine solution with gentle orbital shaking (100 rpm) at RT for $30 \mathrm{~min}$. Table 1 reports the observed alterations in the mats' morphology and architecture following each washing procedure. In all cases, the nanofibers, originally straight, merged/fused and entangled with each other, forming interfiber bonding, mostly at the intersection points, due to the heat applied. Overall, the fibers morphology and nanofibrous meshes 
porosity, which are important requirements for biomedical applications, could not be retained.

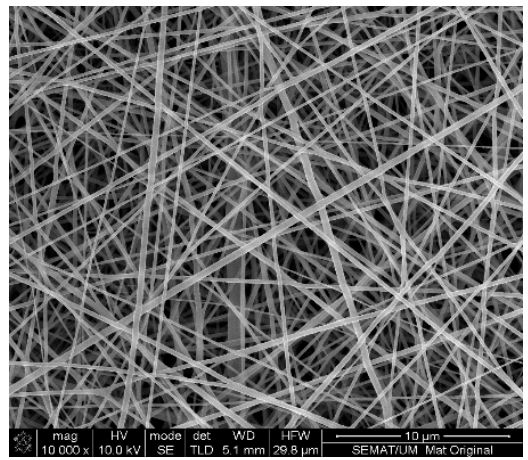

(a)

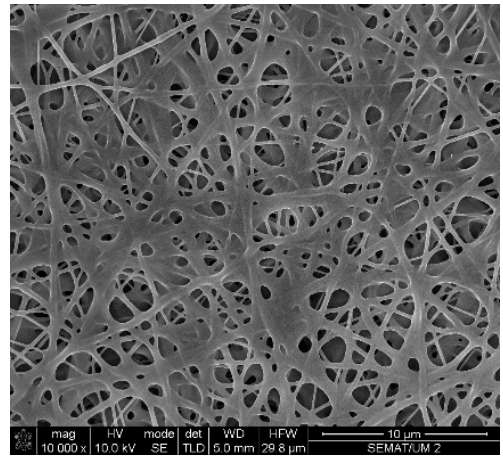

(b)

Figure 1. FEG-SEM micrograph of an 80/20 PVA/CA mat, (a) before and (b) after crosslinking using $15 \mathrm{~mL}$ of GA at $2.56 \mathrm{M}$.

Table 1. Treatments applied for the elimination of GA entrapped within the nanofibrous mats.

\begin{tabular}{|c|c|c|c|}
\hline Process & Sonication & Orbital Shaker & Glycine \\
\hline Duration (min) & 15 vs. 30 & 15 vs. 30 & 15 \\
\hline \multirow{2}{*}{$\begin{array}{c}\text { Structure } \\
\text { (treatment time or glycine } \\
\text { concentration) }\end{array}$} & (15 min) & (15 $\min )$ & $(0.5 \% \mathrm{v} / \mathrm{v})$ \\
\hline & $(30 \mathrm{~min})$ & $(30 \mathrm{~min})$ & $(2.0 \% \mathrm{v} / \mathrm{v})$ \\
\hline Temperature $\left({ }^{\circ} \mathrm{C}\right)$ & RT & 37 & 37 \\
\hline
\end{tabular}

To retain the original structure of the meshes a second approach was examined in which the volume of GA was reduced to $6 \mathrm{~mL}$, while maintaining the $60^{\circ} \mathrm{C}$ of treatment for $7 \mathrm{~h}$. After the crosslinking process, the meshes architectural morphology was almost unaltered when compared to the uncrosslinked meshes (Figure 2a). Additionally, their stability in aqueous medium was guaranteed (Figure 2b). As extra content of GA was not detected on the fibers, drying and washing procedures were neglected. Still, possible GA residues could be eliminated during storage in a controlled environment $\left(41 \% \mathrm{RH}\right.$ and $\left.19^{\circ} \mathrm{C}\right)$. The average diameters of the nanofibers increased slightly to 200, 238, and $278 \mathrm{~nm}$ for 100/0, 90/10, and 80/20 PVA/CA, respectively, when compared to the uncrosslinked surfaces (exception 100PVA). This occurred due to the interaction of the double aldehyde groups of GA with the hydroxyl groups of the polymers. Regardless, this increment was not significant. The largest diameters were obtained on the 80/20 samples, which may be explained by the degree of acetylation (39.8\%) of CA. 


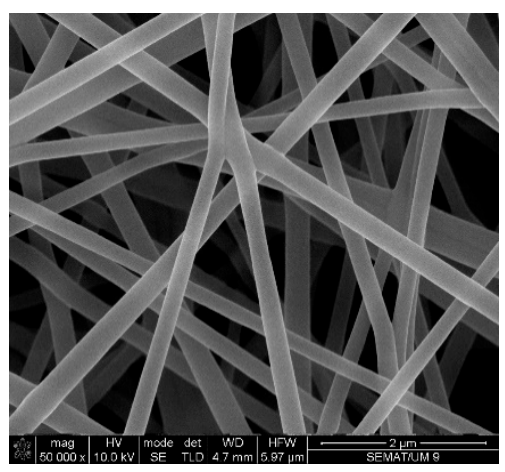

(a)

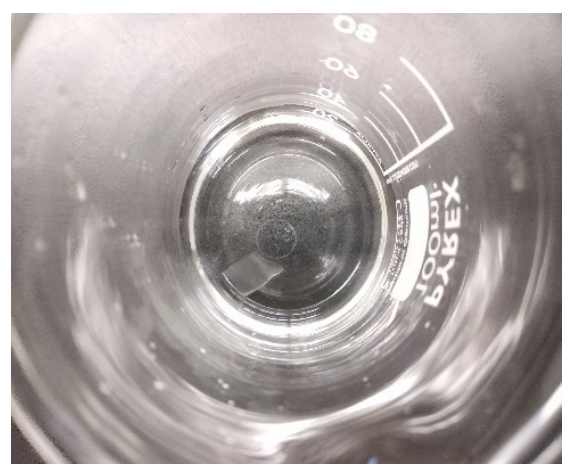

(b)

Figure 2. FEG-SEM micrograph of an 80/20 PVA/CA mat, (a) after crosslinking with an optimal volume of GA $(2.56 \mathrm{M})$. (b) Confirmation of mat stability in water after $24 \mathrm{~h}$ immersion.

\section{Conclusions}

The main goal of this research was to uncover an effective, green crosslinking process that did not affect substantially the original structure of the electrospun meshes. After several tests, it was concluded that the smallest amount of GA $(6 \mathrm{~mL})$, applied at $60^{\circ} \mathrm{C}$ for $7 \mathrm{~h}$, was sufficient to establish acetal bonds between the hydroxyl groups of PVA and CA and the aldehyde groups of GA. Using these conditions, a stable and resilient fibrous network was attained capable of sustaining prolonged immersion in aqueous media. Further, the architecture of the meshes was not impaired due to the excess of GA, which is often described, allowing the uniform porosity and morphology to prevail without the introduction of defects. These requirements are extremely important for applications in wound healing, as these mats should allow oxygen exchange, to maintain a moist environment and to stimulate cell development around the wound, while avoiding the unwanted entry of microorganisms.

Author Contributions: conceptualization: M.A.T.; writing original draft: M.A.T.; revision and editing: J.C.A. and H.P.F.; supervision: H.P.F.; funding acquisition: M.T.P.A. and H.P.F. All authors have read and agreed to the published version of the manuscript.

Funding: This research was funded by the Portuguese Foundation for Science and Technology (FCT), grant number PTDC/CTM-TEX/28074/2017 (POCI-01-0145-FEDER-028074), UID/CTM/002 64/2021 and SFRH/BD/148930/2019.

Institutional Review Board Statement: Not applicable.

Informed Consent Statement: Not applicable.

Data Availability Statement: Not applicable.

Acknowledgments: Authors acknowledge the Portuguese Foundation for Science and Technology (FCT), FEDER funds by means of Portugal 2020 Competitive Factors Operational Program (POCI) and the Portuguese Government (OE) for funding the project PEPTEX with reference PTDC/CTMTEX/28074/2017 (POCI-01-0145-FEDER-028074). Authors also acknowledge project UID/CTM/0026 4/2021 of Centre for Textile Science and Technology (2C2T), funded by national funds through FCT/MCTES. M.A.T. acknowledges FCT for the PhD grant with reference SFRH/BD/148930/2019. SEM studies were performed at the Materials Characterization Services of the University of Minho (SEMAT/UM).

Conflicts of Interest: The authors declare no conflict of interest.

\section{Abbreviations}

The following abbreviations are used in this manuscript:

PVA Poly(vinyl alcohol)

CA Cellulose acetate 


$\begin{array}{ll}\text { CW } & \text { Chronic wounds } \\ \text { GA } & \text { Glutaraldehyde } \\ \text { RH } & \text { Relative humidity } \\ \text { RT } & \text { Room temperature }\end{array}$

\section{References}

1. Kumar, A.; Behl, T.; Chadha, S. A rationalized and innovative perspective of nanotechnology and nanobiotechnology in chronic wound management. J. Drug Deliv. Sci. Technol. 2020, 60, 101930, doi:10.1016/j.jddst.2020.101930.

2. Las, K.; Igartua, M.; Santos-vizcaino, E.; Maria, R. Chronic wounds: Current status, available strategies and emerging therapeutic solutions. J. Control. Release 2020, 328, 532-550, doi:10.1016/j.jconrel.2020.09.039.

3. Omar, A.; Wright, J.B.; Schultz, G.; Burrell, R.; Nadworny, P. Microbial Biofilms and Chronic Wounds. Microorganisms 2017, 5, 9, doi:10.3390/microorganisms5010009.

4. Wu, Y.K.; Cheng, N.C.; Cheng, C.M. Biofilms in Chronic Wounds: Pathogenesis and Diagnosis. Trends Biotechnol. 2018, 37, 505517, doi:10.1016/j.tibtech.2018.10.011.

5. Mirzadegan, E.; Golshahi, H.; Kazemnejad, S. Current evidence on immunological and regenerative effects of menstrual blood stem cells seeded on scaffold consisting of amniotic membrane and silk fibroin in chronic wound. Int. Immunopharmacol. 2020, 85, 106595, doi:10.1016/j.intimp.2020.106595.

6. Zhao, R.; Liang, H.; Clarke, E.; Jackson, C.; Xue, M. Inflammation in chronic wounds. Int. J. Mol. Sci. 2016, 17, 2085, doi:10.3390/ijms17122085.

7. Teixeira, M.A.; Amorim, M.T.P.; Felgueiras, H.P. Cellulose Acetate in Wound Dressings Formulations: Potentialities and Electrospinning Capability. In Proceedings of the XV Mediterranean Conference on Medical and Biological Engineering and ComputingMEDICON 2019, Coimbra, Portugal, 26-28 September 2019; Springer International Publishing: Cham, Switzerland, 2020; Volume 76, pp. 1515-1525, doi:10.1007/978-3-030-31635-8_149.

8. Chen, Q.; Wu, J.; Liu, Y.; Li, Y.; Zhang, C.; Qi, W.; Yeung, K.W.K.; Wong, T.M.; Zhao, X.; Pan, H. Electrospun chitosan/PVA/bioglass Nanofibrous membrane with spatially designed structure for accelerating chronic wound healing. Mater. Sci. Eng. C 2019, 105, 110083, doi:10.1016/j.msec.2019.110083.

9. Chao, S.; Li, Y.; Zhao, R.; Zhang, L.; Li, Y.; Wang, C.; Li, X. Synthesis and characterization of tigecycline-loaded sericin/poly(vinyl alcohol) composite fibers via electrospinning as antibacterial wound dressings. J. Drug Deliv. Sci. Technol. 2018, 44, 440-447, doi:10.1016/j.jddst.2018.01.022.

10. Miguel, S.P.; Figueira, D.R.; Simões, D.; Ribeiro, M.P.; Coutinho, P.; Ferreira, P.; Correia, I.J. Electrospun polymeric nanofibres as wound dressings: A review. Colloids Surf. B Biointerfaces 2018, 169, 60-71, doi:10.1016/j.colsurfb.2018.05.011.

11. Teixeira, M.A.; Amorim, M.T.P.; Felgueiras, H.P. Poly (Vinyl Alcohol)-Based Nanofibrous Electrospun Scaffolds for Tissue Engineering Applications. Polymers 2020, 12, 7, doi:10.3390/polym12010007.

12. Felgueiras, H.P.; Homem, N.C.; Teixeira, M.A.; Ribeiro, A.R.M.; Antunes, J.C.; Amorim, M.T.P. Physical, thermal, and antibacterial effects of active essential oils with potential for biomedical applications loaded onto cellulose acetate/polycaprolactone wet-spun microfibers. Biomolecules 2020, 10, 1129, doi:10.3390/biom10081129.

13. Felgueiras, H.P.; Teixeira, M.A.; Tavares, T.D.; Homem, N.C.; Zille, A.; Amorim, M.T.P. Antimicrobial action and clotting time of thin, hydrated poly (vinyl alcohol)/cellulose acetate films functionalized with LL37 for prospective wound-healing applications. Appl. Polym. 2019, 137, 48626, doi:10.1002/app.48626.

14. Teixeira, M.A.; Paiva, M.C.; Amorim, M.T.P.; Felgueiras, H.P. Electrospun Nanocomposites Containing Cellulose and Its Derivatives Modified with Specialized Biomolecules for an Enhanced Wound Healing. Nanomaterials 2020, 10, 557, doi:10.3390/nano10030557.

15. Destaye, A.G.; Lin, C.; Lee, C. Glutaraldehyde Vapor Cross-linked Nanofibrous PVA Mat with in Situ Formed Silver Nanoparticles. ACS Appl. Mater. Interfaces 2013, 5, 4745-4752, doi:10.1021/am401730x.

16. Vashisth, P.; Pruthi, V. Synthesis and characterization of crosslinked gellan/PVA nanofibers for tissue engineering application. Mater. Sci. Eng. C 2016, 67, 304-312, doi:10.1016/j.msec.2016.05.049.

17. Wang, W.; Jin, X.; Zhu, Y.; Zhu, C.; Yang, J.; Wang, H.; Lin, T. Effect of vapor-phase glutaraldehyde crosslinking on electrospun starch fibers. Carbohydr. Polym. 2016, 140, 356-361, doi:10.1016/j.carbpol.2015.12.061.

18. Teixeira, M.A.; Amorim, M.T.P.; Felgueiras, H.P. PVA/CA based electrospun nanofibers: Influence of processing parameters in the fiber diameter. IOP Conf. Ser. Mater. Sci. Eng. 2019, 634, 012040, doi:10.1088/1757-899X/634/1/012040. 